even be harmful. ${ }^{2-4}$ Clearly the standard practice of debriefing after disasters and catastrophes should end. But for managing the chaos, material losses, grief, and anger-for example, after a terrorist attack-no conclusive evidence is available yet on how a disaster stricken community regains control.

According to the NICE guideline, treatment is necessary when, in the aftermath of trauma, posttraumatic stress disorder, depression, suicidality, addiction, medically unexplained physical symptoms, or dissociative disorders arise. The risk of developing post-traumatic stress disorder after trauma is $8-13 \%$ for men and $20-30 \%$ for women, ${ }^{5}$ with a 12 month prevalence of $1.3 \%$ to $3.9 \%,{ }^{6}$ creating a huge burden on society.

Post-traumatic stress disorder is primarily a deregulation of the fear system. Fear is a necessary emotion at times of danger, and is followed by a stress response-fighting, freezing, or fleeing. This survival system depends on appraising threats in order to initiate survival behaviour. ${ }^{7}$ Once the threat or trauma is over, the fear system normally calms down after a few days or weeks. In post-traumatic stress disorder this system fails to reset to normal, keeping the sufferer hyperalert, scanning for dangerous cues as if the event may happen again.

The disorder is thus characterised by involuntary, persistent remembering or reliving the traumatic event in flashbacks, vivid memories, and recurrent dreams. The individual tries to avoid recollecting the trauma, by avoiding its location or television programmes about it. Persistent symptoms of increased arousal, such as hypervigilance, exaggerated startle response, sleeping problems, irritability, and difficulty concentrating, are part of the disorder. Comorbidities such as depression, substance abuse, and other anxiety disorders are the norm rather than the exception. Emotional numbing, such as feeling detached from others, is also seen-for example in soldiers after peacekeeping missions.

The NICE guideline systematically reviews the evidence for both psychological and pharmacological interventions. As first line treatment NICE recommends trauma focused psychological therapy. Both published and unpublished data indicate only limited efficacy for a small number of pharmacological interventions, so NICE recommends not using drugs as first line treatment.

The most effective treatment for resetting the fear system is cognitive behaviour therapy. ${ }^{8}$ By imaginary exposure to the traumatic event the fear reaction will decrease in time. Concepts about the self that are prompted by the event, such as feeling "weak," guilty, or invulnerable, are replaced by more realistic cognitions. The guideline also supports, albeit not as strongly, treatment with eye movement desensitisation reprocessing, which uses a distractive manoeuvre of bilateral stimulation after exposure to decrease the emotional lability related to the trauma.

An unanswered question remains whether the heightened sense of fear in post-traumatic stress disorder is related to the event or to the suppression of unusually strong emotions of grief and aggression brought about by the traumatic experience. ${ }^{9}$ Like Summerfield we believe that more attention should be paid to the meaning of tragic experiences, shattering the sufferer's views about life, ${ }^{10}$ although evidence on this aspect is lacking. We also agree with the guideline about paying attention to the common comorbidities of post-traumatic stress disorder (such as depression and anxiety), though the evidence is still quite limited. ${ }^{1}$

Despite the existence of effective psychosocial treatments, a third of patients will not recover fully. ${ }^{11}$ Comorbidity, chronicity, and the accumulation of acute and chronic stress may explain the limited response to treatment. Also, from an evolutionary viewpoint one can see how "the gift of nature" of remembering and learning from danger may restrict what is attainable in treating post-traumatic stress disorder. ${ }^{12}$ We cannot delete the memory of trauma.

Berthold P R Gersons professor of psychiatry

(b.p.gersons@amc.uva.nl)

Miranda Olff associate professor of psychotraumatology

Department of Psychiatry, Academic Medical Center, University of Amsterdam, 1105 BC Amsterdam, Netherlands

Competing interests: None declared.

1 National Institute for Clinical Excellence. The management of post traumatic stress disorder in primary and secondary care. London: NICE, 2005.

2 Rose S, Bisson J, Wessely S. Psychological debriefing for preventing post traumatic stress disorder (post traumatic stress disorder). Cochrane Database Syst Rev 2002. Issue 2:CD000560.

Gist R, Devilly GJ, Post-trauma debriefing: the road too frequently travelled. Lancet 2002;360:741-2.

4 van Emmerik AA, Kamphuis JH, Hulsbosch AM, Emmelkamp PM. Single session debriefing after psychological trauma: a meta-analysis. Lancet 2002;360:766-71.

5 Kessler RC, Sonnega A, Bromet E, Hughes M, Nelson CB. Posttraumatic stress disorder in the national comorbidity survey. Arch Gen Psychiatr 1995;52:1048-60.

6 Creamer M, Burgess P, McFarlane A. Posttraumatic stress disorder: Findings from the Australian national survey of mental health and well-being. Psychol Med 2001;31:1237-47

7 Olff M, Langeland W, Gersons BPR. Effects of appraisal and coping on the neuroendocrine response to extreme stress. Neurosci Biobehav Rev (in press).

8 Foa EB, Keane T, Friedman M. Effective treatments for post traumatic stress disorder:practice guidelines from the International Society for Traumatic Stress Studies. New York: Guilford Press, 2000.

9 Gersons BPR, Carlier IVE, Lamberts RD, van der Kolk B. A randomized clinical trial of brief eclectic psychotherapy in police officers with clinical trial of brief eclectic psychotherapy in police offices
posttraumatic stress disorder. J Traumatic Stress 2000;13:333-47.

posttraumatic stress disorder.J Traumatic Stress 2000;13:333-47.
10 Summerfield D. The invention of post-traumatic stress disorder and the 10 Summerfield D. The invention of post-traumatic stress disorde
social usefulness of a psychiatric category. BMJ 2001;322:95-8.

1 Bradley R, Greene J, Russ E, Dutra L, Westen D. A multidimensional meta-analysis of psychotherapy for post traumatic stress disorder. Am Psychiatry 2005;162:214-27.

12 Le Doux JE. The emotional brain. New York: Simon and Schuster, 1996.

\title{
Management of chronic kidney disease
}

\section{Primary and secondary care need to set up a model of combined care}

$\mathrm{E}$ pidemiological studies have shown that renal disease is common. In the United States, the third national health and nutrition survey
(Nhanes III) has shown that $4.3 \%$ of the population has chronic kidney disease with a glomerular filtration rate of $30-59 \mathrm{ml} / \mathrm{min} / 1.73 \mathrm{~m}^{2}$, and $0.2 \%$ has chronic kidney disease with a glomerular filtration rate of less than $15-29 \mathrm{ml} / \mathrm{min} / 1.73 \mathrm{~m}^{2}$. In the United Kingdom, 
screening for renal disease by retrospective surveys of plasma creatinine measurements from chemical pathology laboratories serving defined populations has shown a similar prevalence of more severe chronic kidney disease $\left(0.2-0.5 \%\right.$ general population). ${ }^{23}$ In both studies, patients were followed longitudinally; very few developed end stage renal disease, as the major cause of death was cardiovascular disease. So what model of care should we use to look after this large number of patients with varying degrees of chronic kidney disease?

Increasing numbers of studies have shown that the presence of chronic kidney disease is an independent and significant cardiovascular risk factor in the general population and in those with pre-existing cardiovascular disease. ${ }^{45}$ Furthermore, the complications of renal failure such as anaemia and hyperparathyroidism develop at higher glomerular filtration rates than usually thought and are common when the rate is as high as $30-40 \mathrm{ml} / \mathrm{min}$. In the study of Stevens et al, haemoglobin was less than $11 \mathrm{~g} / \mathrm{dl}$ in $27.5 \%$ of the patients with chronic kidney disease not referred to renal clinics. ${ }^{2}$

Patients who have potentially reversible causes of renal failure or whose renal function is deteriorating rapidly need to be identified to allow for rapid assessment by a nephrologist. The question remains how best to manage the remaining large cohort of patients with stable chronic kidney disease of varying degrees. The use of calculated glomerular filtration rate is likely to identify patients with less severe degrees of chronic kidney disease, who may be missed if serum creatinine is used to assess kidney function. We do not have enough nephrologists or nephrology outpatient clinics to manage the workload that this would generate, and evidence shows that using nephrology outpatient clinics is not the most effective means of managing chronic diseases. ${ }^{6}$ Such patients would be best managed in a partnership arrangement between primary and secondary care. In this model, many professional groups including general practitioners with a specialist interest, specialist nurses, pharmacists, and dieticians all have a role in the management of the chronic condition. Patients also need to take on a greater responsibility for their own care.

Patients with a glomerular filtration rate of less than $15 \mathrm{ml} / \mathrm{min}$ are highly likely to require renal replacement therapy and will need close follow-up to prepare them for this event. The renal national service framework has highlighted the importance of involving patients in this process, and considerable time will also be needed to inform them fully of the treatment options available. ${ }^{7}$ Such care can best be provided in a nephrology clinic, with access to support from renal specialist nurses, renal dieticians, and vascular access surgeons.

Patients whose glomerular filtration rate is between $15 \mathrm{ml} / \mathrm{min}$ and $30 \mathrm{ml} / \mathrm{min}$ may also require considerable input from specialists. However, many of these patients remain stable for long periods, and the interventions required could easily be managed by a specialist nursing clinic with support from a nephrologist. Seemingly complex issues such as the recognition and treatment of renal anaemia and hyperparathyroidism can be managed by using practice guidelines.
For the larger number of patients with a glomerular filtration rate between $30 \mathrm{ml} / \mathrm{min}$ and $60 \mathrm{ml} / \mathrm{min}$ the main interventions required are basic ones. Common approaches exist to preventing the progression of chronic kidney disease and cardiovascular disease. These include tight control of blood pressure, correcting lipid abnormalities, and various lifestyle changes including the cessation of smoking. ${ }^{89}$ The general practitioner with a specialist interest and many non-specialist nurses working within primary care should be able to contribute to this process, as long as they are able to work to guidelines and have ready access to medical support from general practitioners and advice from renal specialist nurses and nephrologists.

The challenge is for primary and secondary care to set up together the necessary systems to implement such a model. These systems may require novel approaches to commissioning and clarity with regard to clinical responsibility for the patients. As the patients move through this pathway, they will need to be managed according to guidelines, with targets for the control of blood pressure, diabetes, lipids, and smoking. This will have to be provided in a patient centred environment, which gives the patient a role and an incentive for achieving these goals. With optimum treatment cardiovascular complications can be reduced and patients can have the progression to end stage renal disease delayed by many years.

Considering this approach to managing chronic renal disease is the only way in which we are likely to cope with this large cohort of patients and to produce the results that will reduce the impact of end stage renal failure and reap a sizeable financial reward for the health services.

Andrew Frankel consultant nephrologist

Renal Unit, Charing Cross Hospital, Fulham Palace Road, London W6 8RF

(a.frankel@imperial.ac.uk)

Edwina Brown professor of renal medicine

Faculty of Medicine, Imperial College, London SW7 2AZ

David Wingfield general practitioner

Brook Green Medical Centre, London W6 7DR

Competing interests: None declared.

1 Coresh J, Astor BC, Greene T, Eknoyan G, Levey AS. Prevalence of chronic kidney disease and decreased renal function in the adult US chronic kidney disease and decreased renal function in the adult US
population: third national health and nutrition examination survey. Am J Kidney Dis 2003;41:1-12

2 John R, Webb M, Young A, Stevens PE. Unreferred chronic kidney disease: a longitudinal study. Am J Kidney Dis 2004;43:825-36.

3 Drey N, Roderick P, Mullee M, Rogerson M. A population-based study of the incidence and outcomes of diagnosed chronic kidney disease. Am J Kidney Dis 2003;42:677-84.

4 Go AS, Chertow GM, Fan D, McCulloch CE, Hsu C. Chronic kidney disease and the risks of death, cardiovascular events, and hospitalisation. $N$ EnglJ Med 2004;351:1296-305.

5 Anavekar NS, McMurray JJV, Velazquez EJ, Solomon SD, Kober L, Rouleau JL, et al. Relation between renal dysfunction and cardiovascular Rouleau JL, et al. Relation between renal dystunction and cardiovascular
outcomes after myocardial infarction. N Engl J Med 2004;351:1285-95.

outcomes after myocardial infarction. N EnglJ Med 2004;351:1285-95.
Lewis R, Dixon J. Rethinking management of chronic diseases. BMJ 2004;328:220-2.

7 Department of Health. National service framework for renal services: part one-dialysis and transplantation. January 2004. www.dh.gov.uk/ PublicationsAndStatistics/Publications

PublicationsPolicyAndGuidance/

PublicationsPolicyAndGuidanceArticle/fs/

en?CONTENT_ID = 4070359\&chk = ZX5LF3 (accessed 9 Mar 2005).

8 Kidney Disease Outcomes Quality Initiative. Clinical practice guidelines on hypertension and antihypertensive agents in chronic kidney disease. on hypertension and antihypertensive

9 Fried LF, Orchard TJ, Kasiske BL for the Lipids and Renal Disease Progression Meta-Analysis Study Group. Effect of lipid reduction on the progression of renal disease: a meta-analysis. Kidney Int 2001;59:260-9. 